\title{
Biosynthesis of caffeic acid in Escherichia coli using its endogenous hydroxylase complex
}

Yuheng $\operatorname{Lin}^{1}$ and Yajun Yan ${ }^{2}$

\begin{abstract}
Background: Caffeic acid (3,4-dihydroxycinnamic acid) is a natural phenolic compound derived from the plant phenylpropanoid pathway. Caffeic acid and its phenethyl ester (CAPE) have attracted increasing attention for their various pharmaceutical properties and health-promoting effects. Nowadays, large-scale production of drugs or drug precursors via microbial approaches provides a promising alternative to chemical synthesis and extraction from plant sources.

Results: We first identified that an Escherichia coli native hydroxylase complex previously characterized as the 4hydroxyphenylacetate 3 -hydroxylase (4HPA3H) was able to convert p-coumaric acid to caffeic acid efficiently. This critical enzymatic step catalyzed in plants by a membrane-associated cytochrome P450 enzyme, $p$-coumarate 3hydroxylase $(\mathrm{C} 3 \mathrm{H})$, is difficult to be functionally expressed in prokaryotic systems. Moreover, the performances of two tyrosine ammonia lyases (TALS) from Rhodobacter species were compared after overexpression in E. coli. The results indicated that the TAL from $R$. capsulatus $(R C)$ possesses higher activity towards both tyrosine and L-dopa. Based on these findings, we further designed a dual pathway leading from tyrosine to caffeic acid consisting of the enzymes 4HPA3H and RcTAL. This heterologous pathway extended E. coli native tyrosine biosynthesis machinery and was able to produce caffeic acid $(12.1 \mathrm{mg} / \mathrm{L})$ in minimal salt medium. Further improvement in production was accomplished by boosting tyrosine biosynthesis in E. coli, which involved the alleviation of tyrosine-induced feedback inhibition and carbon flux redirection. Finally, the titer of caffeic acid reached $50.2 \mathrm{mg} / \mathrm{L}$ in shake flasks after 48-hour cultivation.

Conclusion: We have successfully established a novel pathway and constructed an E. coli strain for the production of caffeic acid. This work forms a basis for further improvement in production, as well as opens the possibility of microbial synthesis of more complex plant secondary metabolites derived from caffeic acid. In addition, we have identified that TAL is the rate-limiting enzyme in this pathway. Thus, exploration for more active TALs via bioprospecting and protein engineering approaches is necessary for further improvement of caffeic acid production.
\end{abstract}

\section{Background}

Caffeic acid (3,4-dihydroxycinnamic acid) is a natural phenolic compound initially found in plants. Previous studies on its biological activities suggested that caffeic acid possesses anti-oxidant [1,2], anti-virus [3], anti-cancer [4] and anti-inflammatory properties [5]. Moreover, its derivative, caffeic acid phenethyl ester (CAPE), has drawn great attention because of its demonstrated therapeutic effects including its potential as an anti-diabetic

\footnotetext{
* Correspondence: yajunyan@uga.edu

${ }^{2}$ Biochemical Engineering Program, Faculty of Engineering, the University of Georgia, Athens, GA 30602, USA

Full list of author information is available at the end of the article
}

and liver-protective agent as well as an anti-tumor drug for human breast cancer treatment [6,7].

Caffeic acid is one of the pivotal intermediates of plant phenylpropanoid pathway starting from the deamination of phenylalanine which generates cinnamic acid. Followed by a two-step sequential hydroxylation at the 4and 3- position of the benzyl ring, cinnamic acid is converted into caffeic acid via $p$-coumaric acid $[8,9]$. The involved enzymes, cinnamate 4-hydroxylase $(\mathrm{C} 4 \mathrm{H})$ and p-coumarate 3-hydroxylase $(\mathrm{C} 3 \mathrm{H})$ are plant-specific cytochrome P450 dependent monooxygenases. Due to their instability and membrane-bound property, the purification and characterization of these enzymes are quite challenging, particularly for $\mathrm{C} 3 \mathrm{H}$ [10]. It was also suggested
C Biomed Central

(C) 2012 Lin and Yan; licensee BioMed Central Ltd. This is an Open Access article distributed under the terms of the Creative Commons Attribution License (http://creativecommons.org/licenses/by/2.0), which permits unrestricted use, distribution, and reproduction in any medium, provided the original work is properly cited. 
that the hydroxylation at the 3-position could also occur after $p$-coumaric acid is esterified, which does not generate caffeic acid as the intermediate $[8,11]$. Recently, genes and enzymes involved in caffeic acid biosynthesis were also reported in the actinomycete Saccharothrix espanaensis. A tyrosine ammonia lyase (TAL) encoded by sam8 and a microbial $\mathrm{C} 3 \mathrm{H}$ encoded by sam5 are responsible for the conversion of tyrosine to $p$-coumaric acid and then to caffeic acid, respectively [12].

Currently, caffeic acid is commonly produced by extraction from plant sources, such as coffee beans. Chemical or enzymatic hydrolysis of caffeoylquinic acid derivatives is also employed to produce caffeic acid [13,14]. Like many other secondary metabolites, caffeic acid derivatives are usually accumulated at low levels in plants and hence the isolation of these compounds is to some extent difficult and expensive. Microbial conversion provides an alternative approach to caffeic acid production. Sachan et al. reported the co-production of caffeic acid and $p$-hydroxybenzoic acid in Streptomyces caeruleus by feeding $p$-coumaric acid [15]. Over decades, advances in metabolic engineering and synthetic biology enable the production of various plant-specific secondary metabolites in recombinant microorganisms [16-19]. Most recently, the conversion of tyrosine to caffeic acid (the titer was not reported) and ferulic acid $(7.1 \mathrm{mg} / \mathrm{L})$ in $E$. coli was achieved by the co-expression of the enzymes encoded by the sam5 and sam8 from S. espanaensis and an $O$-methyltransferase from Arabidopsis thaliana [20]. However, the above-mentioned studies relied on feeding the direct precursors such as tyrosine and $p$-coumaric acid, which would increase the production cost and can not be preferred for large-scale production. Alternatively, the development of processes that can enable the biosynthesis of these high-value metabolites from simple carbon sources is much more desirable. By utilizing tyrosine-overproducing strains as hosts, the production of several natural compounds such as $L$-dopa, flavonoids, and benzylisoquinoline alkaloids from simple carbon sources has already been achieved [21-23].

In this study, we characterized the E. coli native 4hydroxyphenlacetate 3 -hydroxylase $(4 \mathrm{HPA} 3 \mathrm{H})$ that was capable of hydroxylating $p$-coumaric acid and tyrosine in addition to its native substrate 4-hydroxyphenylacetic acid. Moreover, we found the TAL from Rhodobacter capsulatus was able to accept both tyrosine and $L$-dopa as substrates. Based on these findings, we further designed a novel dual pathway leading from tyrosine to caffeic acid mediated by the enzymes $4 \mathrm{HPA} 3 \mathrm{H}$ and TAL. As shown in Figure 1B, native tyrosine biosynthesis can be extended by the introduction of the $4 \mathrm{HPA} 3 \mathrm{H}$ and TAL, yielding $L$-dopa and $p$-coumaric acid, respectively. Then TAL further converts $L$-dopa to caffeic acid; while $4 \mathrm{HPA} 3 \mathrm{H}$ converts $p$-coumaric acid into caffeic acid as well. Furthermore, by grafting this dual pathway into $E$. coli, we successfully achieved de novo biosynthesis of caffeic acid. This work not only opens the route to the production of caffeic acid from simple carbon sources, but also paves the way to the microbial synthesis of many other phenylpropanoids derived from caffeic acid.

\section{Results and discussion}

Plants and bacteria are very different in cell structure, physiology and genetics. One of the difficulties in reconstructing plant pathways in microbial systems is the availability of functional enzymes that are compatible with the specific microorganism. For the biosynthesis of caffeic acid in plants, two cytochrome P450-dependent monooxygenases are involved, which are $\mathrm{C} 4 \mathrm{H}$ and $\mathrm{C} 3 \mathrm{H}$ [10]. Due to the requirement for anchorage on endoplasmic reticulum, functional expression of these plant P450-dependent enzymes were always problematic in bacterial systems $[10,24]$. Fortunately, TALs identified from various sources can catalyze the direct formation of $p$-coumaric acid from tyrosine bypassing the enzymatic step catalyzed by $\mathrm{C} 4 \mathrm{H}$ [25], and thus, the need for a $\mathrm{C} 4 \mathrm{H}$ was not obligatory. Nevertheless, the need for $\mathrm{C} 3 \mathrm{H}$ still remains. Although an alternative microbial $\mathrm{C} 3 \mathrm{H}$ was identified from $S$. espanaensis, its activity seems to be low, which limits its applications [20].

\section{p-Coumaric Acid Hydroxylation by $4 \mathrm{HPA} 3 \mathrm{H}$}

One of the most challenging steps in reconstructing plant phenylpropanoid pathway in E. coli is the 3-hydroxylation of $p$-coumaric acid, because all $\mathrm{C} 3 \mathrm{Hs}$ identified in plants are cytochrome $\mathrm{P} 450$-dependent monooxygenases and are hard to be functionally expressed in bacterial systems [10]. Therefore, the exploration of alternative enzymes compatible with $E$. coli is necessary. By examining $E$. coli native enzymes and pathways related to metabolism of aromatic compounds, we reasoned that the $4 \mathrm{HPA} 3 \mathrm{H}$ complex encoded by the operon $h p a B C$ involved in the 4-hydroxyphenylacetate (4-HPA) degradation may play the role of $\mathrm{C} 3 \mathrm{H}[26,27]$. This enzyme complex can accept a broad range of substrates and has been applied to produce $L$-dopa and hydroxytyrosol from tyrosine and 4-tyrosol, respectively [23,26-28]. Because $p$-coumaric acid is similar to 4-HPA, tyrosine and 4-tyrosol in molecular structure (Figure 2), we reasoned that the catalytic pocket of $4 \mathrm{HPA} 3 \mathrm{H}$ should be able to accommodate $p$-coumaric acid as well.

To test this hypothesis, we first cloned $h p a B C$ into a high-copy expression vector pZE12-luc. After over-expressing this enzyme complex in wild type E. coli BW25113, crude extract was prepared for in vitro enzyme assay. Our results indicate that $4 \mathrm{HPA} 3 \mathrm{H}$ complex is capable of converting $p$-coumaric acid to caffeic acid in the presence of 


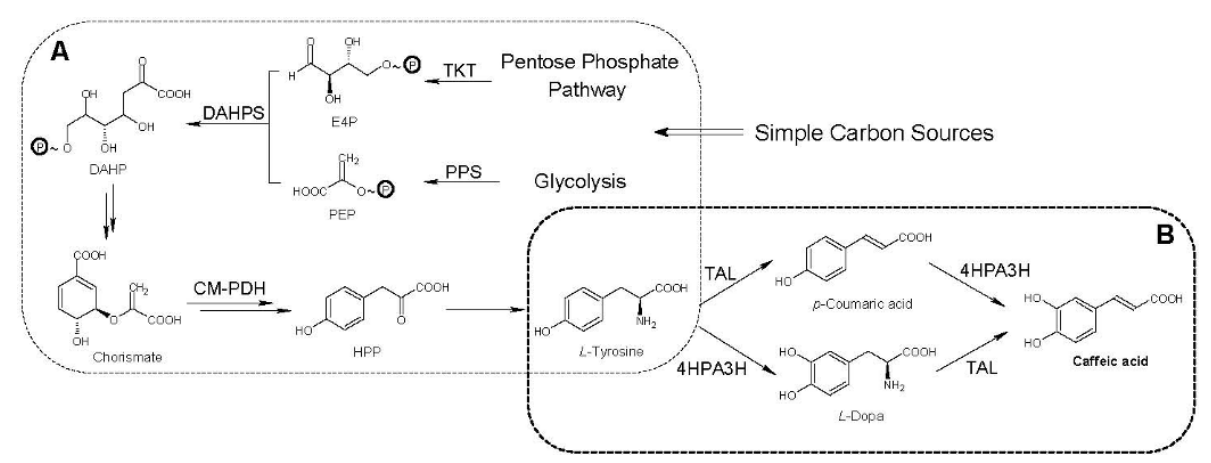

Figure 1 Proposed caffeic acid biosynthetic pathway. (A) Native tyrosine biosynthetic pathway in E. coli. (B) The artificial dual pathway mediated by 4HPA3H and TAL for caffeic acid biosynthesis from tyrosine. PPS: phosphoenolpyruvate synthase; TKT: transketolase; CM-PDH: chorismate mutase-prephenate dehydrogenase; DAHPS: 3-deoxy-D-arabino- heptulosonate-7-phosphate synthase; 4HPA3H: 4-

hydroxyphenylacetate 3-hydroxylase; TAL: tyrosine ammonia lyase; E4P: D-erythrose-4-phosphate; PEP: phosphoenolpyruvate; HPP: 4-

hydroxyphenylpyruvate.

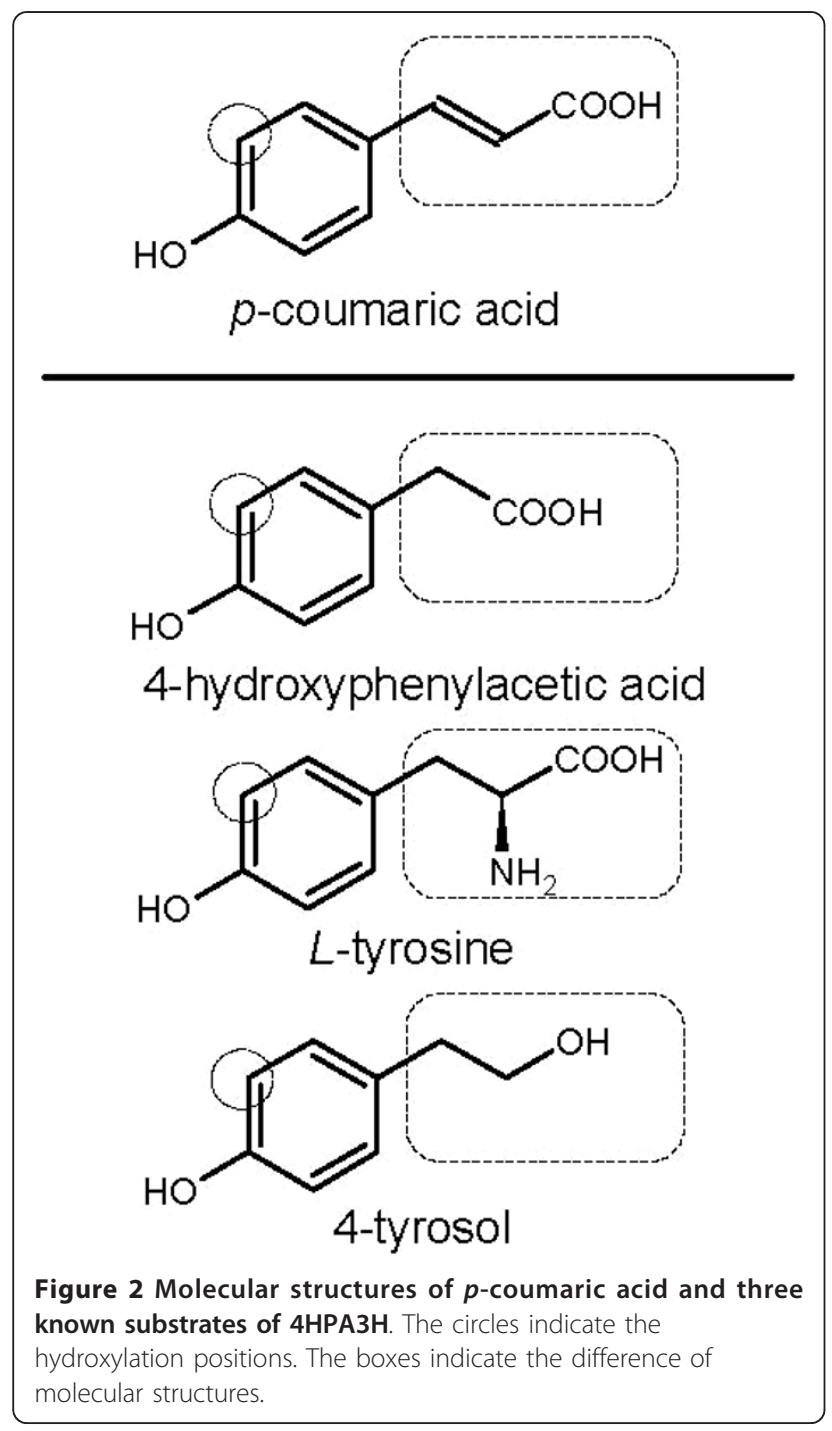

flavin adenine dinucleotide (FAD) and nicotinamide adenine dinucleotide hydride (NADH) (Table 1). Its specific activity toward $p$-coumaric acid $\left(5.37 \times 10^{-3} \mathrm{U} / \mathrm{mg}\right.$ protein) is much higher than its activity toward tyrosine $(2.44$ $\times 10^{-3} \mathrm{U} / \mathrm{mg}$ protein).

Furthermore, we carried out whole-cell conversion studies which reflect the in vivo enzymatic activity. BW25113 harboring pZE-EcHpaBC was able to completely convert $100 \mathrm{mg} / \mathrm{L} p$-coumaric acid to caffeic acid within 3 hours after the induction of isopropyl $\beta-D-1$ thiogalactopyranoside (IPTG), indicating the in vivo activity toward $p$-coumaric acid is high. Meanwhile, no caffeic acid was detected in the culture of the control strain (BW25113 harboring pZE12-luc) even after 20 hours. This phenomenon suggested that although $h p a B C$ exists in the genome of $E$. coli, it is not natively expressed. Thus, over-expression of $h p a B C$ is necessary to obtain adequate $4 \mathrm{HPA} 3 \mathrm{H}$ activity. The result of in vivo enzyme assay showed that the highest conversion rates (within the first hour) from tyrosine to $L$-dopa and from $p$-coumaric acid to caffeic acid are 112.98 and $240.80 \mu \mathrm{mol} \cdot \mathrm{h}^{-1} \cdot \mathrm{gDCW}^{-1}$, respectively (Figure 3 ). For both products, we did not observe obvious intracellular accumulation. Both in vitro and in vivo assay results indicate that $p$-coumaric acid is preferred by $4 \mathrm{HPA} 3 \mathrm{H}$.

Table 1 In vitro activity of 4HPA3H complex

\begin{tabular}{|c|c|c|c|}
\hline Enzyme & Activity tow & Ird Substrate & Ratio $(A: B)$ \\
\hline & $\begin{array}{c}\text { A (tyrosine) } \\
\left(10^{-3} \mathrm{U} / \mathrm{mg} \text { protein }\right)\end{array}$ & $\begin{array}{l}\text { B ( } p \text {-coumaric acid }) \\
\left(10^{-3} \mathrm{U} / \mathrm{mg} \text { protein }\right)\end{array}$ & \\
\hline 4HPA3H & $2.44 \pm 0.11$ & $5.37 \pm 0.31$ & 0.45 \\
\hline
\end{tabular}

One $\mathrm{U}$ (unit) is defined as the amount (1 $\mu$ mole) of product formed per minute. 


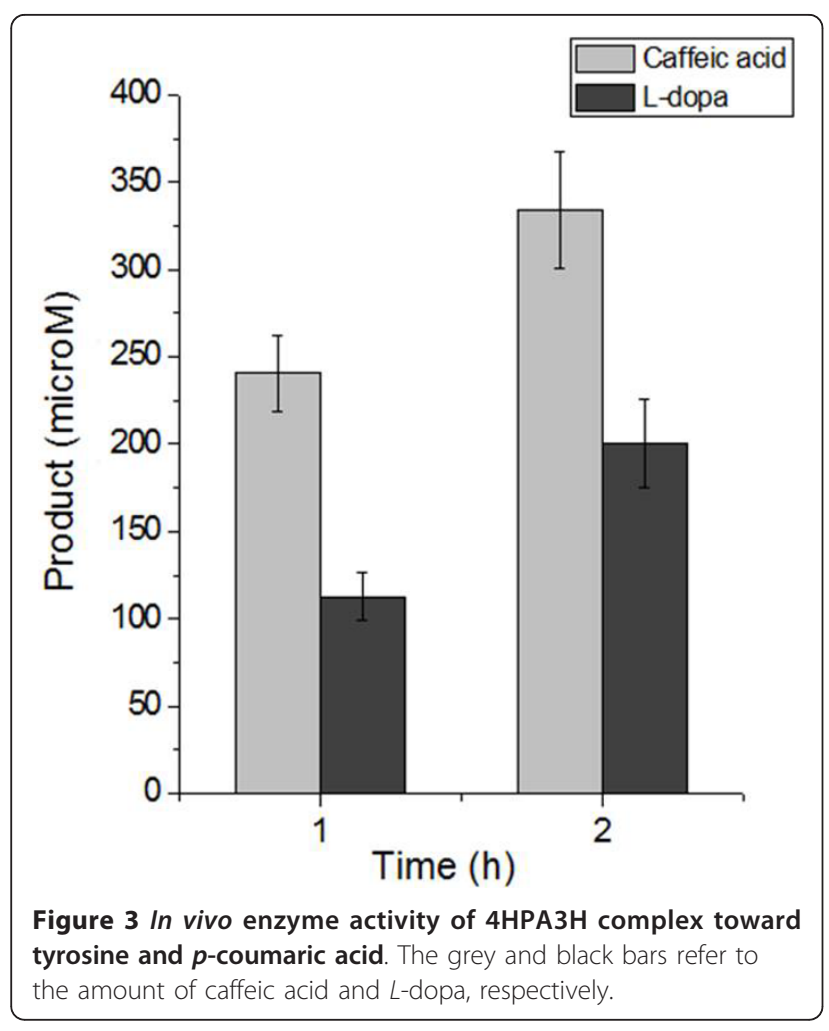

To our knowledge, this is the first report of the $4 \mathrm{HPA} 3 \mathrm{H}$ activity toward $p$-coumaric acid.

\section{Comparison of RcTAL and RsTAL}

Previous studies reported that TALs from $R$. capsulatus $(R c)$ and $R$. sphaeroides ( $R s$ ) catalyze the deamination of tyrosine [25]. In addition, RsTAL can also take $L$-dopa as a substrate [29]. But the activity of RcTAL toward $L$-dopa has not been investigated. To evaluate the performance of the two TALs in E. coli, we performed in vitro enzyme assays using crude extracts. The genes encoding the two TALs were cloned and expressed in E. coli using the plasmids pZE-RcTAL and pZE-RsTAL. Interestingly, both TALs slightly prefer $L$-dopa over their native substrate tyrosine. For RcTAL, the specific activities toward tyrosine and $L$-dopa were $0.93 \times 10^{-3}$ and $1.54 \times 10^{-3} \mathrm{U} / \mathrm{mg}$ protein, respectively. For Rs TAL, the specific activities are $0.80 \times 10^{-3}$ and $1.14 \times 10^{-3} \mathrm{U} / \mathrm{mg}$ protein, respectively. The results indicated that $R c$ TAL is slightly more active than RsTAL toward both substrates (Table 2). As a control, the crude extract of the wild-type E. coli carrying the blank vector did not exhibit any activity.

\section{Production of caffeic Acid in E. coli}

Based on the activities of 4HPA3H and RcTAL, we proposed a novel dual pathway for caffeic acid biosynthesis from tyrosine (Figure 1B). Because E. coli natively biosynthesizes tyrosine, it is expected that the introduction of
Table 2 Comparison of in vitro activity of RCTAL and RsTAL

\begin{tabular}{|c|c|c|c|}
\hline \multirow[t]{2}{*}{ Enzyme } & \multicolumn{2}{|c|}{ Activity toward Substrate* } & \multirow[t]{2}{*}{ Ratio $(A: C)$} \\
\hline & $\begin{array}{c}\text { A (tyrosine) } \\
\left(10^{-3} \mathrm{U} / \mathrm{mg} \text { protein) }\right.\end{array}$ & $\begin{array}{c}C \text { (L-dopa) } \\
\left(10^{-3} \mathrm{U} / \mathrm{mg} \text { protein }\right)\end{array}$ & \\
\hline RCTAL & $0.93 \pm 0.03$ & $1.54 \pm 0.05$ & 0.60 \\
\hline RsTAL & $0.80 \pm 0.13$ & $1.14 \pm 0.03$ & 0.70 \\
\hline
\end{tabular}

* The crude extract of the wild-type E. coli did not show any TAL activity

RcTAL and 4HPA3H can result in the biosynthesis of caffeic acid by utilizing $E$. coli endogenous tyrosine (Figure 1). To achieve this goal, the genes encoding RcTAL and 4HPA3H were amplified and consecutively cloned into a high-copy-number plasmid pZE12-luc under the control of a strong IPTG-inducible promoter $\mathrm{P}_{\mathrm{L}}$ lacO1, generating the plasmid pZE-TH. A ribosome binding site (RBS) was placed upstream of each gene. Strain YL-2 was developed by introducing pZE-TH into wild type $E$. coli strain BW25113 to test this pathway. The production of caffeic acid was carried out in shake flasks using modified M9 minimal salt medium as described in "Methods and Materials". High performance liquid chromatography (HPLC) analysis of the fermentation samples showed that the retention time $(10.1 \mathrm{~min})$ and UV profile of the product were identical to those of the caffeic acid standard, confirming that caffeic acid was produced (Figure 4). The strain YL-2 was able to produce $11.1 \pm 1.1 \mathrm{mg} / \mathrm{L}$ caffeic acid after 24 hours, without obvious accumulation of intermediates including tyrosine, $p$-coumaric acid and $L$-dopa. 48-hour cultivation did not lead to a great increase in caffeic acid production (12.1 $\pm 0.3 \mathrm{mg} / \mathrm{L})$ (Table 3). However, $L$-dopa was accumulated at a concentration of $7.4 \pm 0.2 \mathrm{mg} / \mathrm{L}$.

\section{Construction of tyrosine overproducers}

The addition of $100 \mathrm{mg} / \mathrm{L}$ tyrosine into the cultures of YL2 resulted in a two-fold increase in caffeic acid production (Table 3), suggesting that tyrosine is a limiting precursor for caffeic acid biosynthesis. In wild-type $E$. coli, tyrosine biosynthesis is strictly controlled by several regulatory mechanisms. Two feedback inhibition-sensitive enzymes chorismate mutase-prephenate dehydrogenase (CM-PDH, encoded by tyr $A$ ) and 3-deoxy- $D$-arabino-heptulosonate7-phosphate synthase (DAHPS, encoded by aroG) were identified as the major regulatory components in the tyrosine pathway [30]. The feedback inhibition resistant (fbr) variants $t y r A^{f b r}$ and aro $G^{f b r}$ have already been developed and applied in tyrosine production [30,31]. In addition, the availability of erythrose-4-phosphate (E4P) and phosphoenolpyruvate (PEP) is extremely critical to tyrosine biosynthesis (Figure 1A). Over-expression of PEP synthase (PPS, encoded by ppsA) and transketolase (TKT, encoded by $t k t A$ ) was able to increase the availability of PEP and 

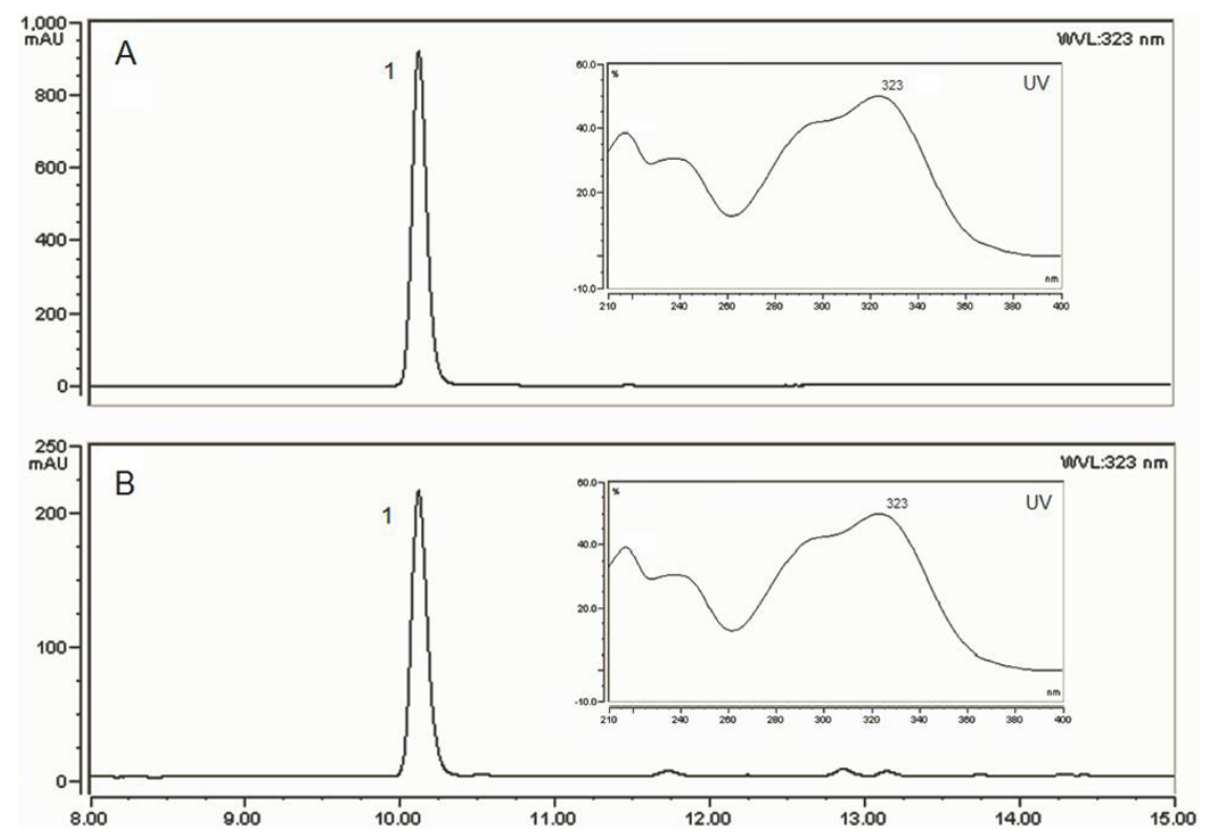

Figure 4 HPLC analysis of caffeic acid produced by engineered E. coli (A) Standard, $\mathbf{5 0} \mathbf{~ m g / L ~ c a f f e i c ~ a c i d . ~ ( B ) ~ A ~ s a m p l e ~ t a k e n ~ f r o m ~ t h e ~}$ fermentation culture of YL-2 after 24 hours. Peak 1 corresponded to caffeic acid. The retention time was 10.1 min. UV absorbance profiles are shown beside the peaks.

E4P, and redirect the carbon flux into the tyrosine pathway [31]. In this work, $t y r A^{f b r}, p p s A, t k t A$ and $a r o G^{f b r}$ were consecutively cloned into a medium-copy-number plasmid pCS27 under the control of $\mathrm{P}_{\mathrm{L}}$ lacO1 promoter as well, generating the plasmid pCS-TPTA. By introducing pCSTPTA into wild type E. coli BW25113, we obtained a recombinant strain YL-3. Compared with wild type strain which produced little tyrosine, YL-3 was able to produce $296.6 \pm 1.0 \mathrm{mg} / \mathrm{L}$ tyrosine in 48 hours, which indicated that over-expression of the four enzymes was effective. Furthermore, the strain YL-1 $(\Delta t y r R)$ was also employed as the host to alleviate the tyrR-mediated regulation [23]. The introduction of PCS-TPTA into YL-1 (yielding strain YL-4) resulted in the accumulation of higher amount of tyrosine ( $426.7 \pm 4.9 \mathrm{mg} / \mathrm{L}$ in $48 \mathrm{~h}$, Table 3$)$. It should be noted that YL-4 exhibited only slight improvement in tyrosine production compared to YL-3 in the first 24 hours. However, its advantage was demonstrated in the following 24 hours. These results are consistent with what were reported previously [30,31].

\section{Improvement of caffeic acid production by tyrosine overproducing strains}

Although YL-4 was able to produce higher amount of tyrosine, this tyrR-deleted strain seemed to be in conflict with pZE-derived plasmids for unknown reasons and did not express the enzymes $4 \mathrm{HPA} 3 \mathrm{H}$ and RcTAL as well as expected. Only a trace amount of caffeic acid $(<0.2 \mathrm{mg} / \mathrm{L})$ and $p$-coumaric acid $(<1 \mathrm{mg} / \mathrm{L})$ but a large amount of tyrosine $(>400 \mathrm{mg} / \mathrm{L})$ were detected in the YL-6 (YL-1

Table 3 Production of caffeic acid and tyrosine by engineered E.coli strains

\begin{tabular}{|c|c|c|c|c|c|c|c|c|}
\hline \multirow[t]{3}{*}{ Strain } & \multicolumn{4}{|c|}{24 hours } & \multicolumn{4}{|c|}{48 hours } \\
\hline & \multirow{2}{*}{$\begin{array}{l}\text { Product } \\
\text { (mg/L) } \\
\text { caffeic acid }\end{array}$} & \multicolumn{3}{|c|}{$\begin{array}{c}\text { Intermediates } \\
(\mathrm{mg} / \mathrm{L})\end{array}$} & \multirow{2}{*}{$\begin{array}{c}\text { Product } \\
\text { (mg/L) } \\
\text { caffeic } \\
\text { acid }\end{array}$} & \multicolumn{3}{|c|}{$\begin{array}{l}\text { Intermediates } \\
(\mathrm{mg} / \mathrm{L})\end{array}$} \\
\hline & & tyrosine & $p$-coumaric acid & L-dopa & & tyrosine & $p$-coumaric acid & L-dopa \\
\hline$Y L-2$ & $11.1 \pm 1.1$ & $<0.2$ & $<0.2$ & $<0.2$ & $12.1 \pm 0.3$ & $<0.2$ & $<0.2$ & $7.4 \pm 0.2$ \\
\hline$Y L-2^{*}$ & $20.2 \pm 1.8$ & $<0.2$ & $<0.2$ & $2.1 \pm 0.3$ & $21.5 \pm 4.0$ & $<0.2$ & $<0.2$ & $14.2 \pm 1.7$ \\
\hline YL-3 & - & $188.9 \pm 5.7$ & - & - & - & $296.6 \pm 1.0$ & - & - \\
\hline$Y L-4$ & - & $218.6 \pm 8.2$ & - & - & - & $426.7 \pm 4.9$ & - & - \\
\hline YL-5 & $30.5 \pm 1.9$ & $17.1 \pm 1.8$ & $2.9 \pm 0.3$ & $15.4 \pm 1.7$ & $50.2 \pm 10.1$ & $25.1 \pm 2.5$ & $<0.2$ & $75.3 \pm 13.6$ \\
\hline
\end{tabular}

-: No production

*: addition of $100 \mathrm{mg} / \mathrm{L}$ tyrosine in the cultures 
harboring pZE-TH and pCS-TPTA) cultures. Thus, we employed wild type E. coli BW25113 as the parent strain. By transforming it with both pZE-TH and pCS-TPTA, we generated the strain YL-5. The titer of caffeic acid in the shake flask fermentation using YL-5 reached $50.2 \pm 10.1$ $\mathrm{mg} / \mathrm{L}$ after $48 \mathrm{~h}$ fermentation which is a 5 -fold increase compared to YL-2. Moreover, we analyzed the intermediates accumulated in the culture. The presence of $25.1 \pm$ $2.5 \mathrm{mg} / \mathrm{L}$ tyrosine indicated that tyrosine availability is no longer the limiting factor for caffeic acid production in the strain YL-5. The accumulation of a large amount of $L$-dopa $(75.3 \pm 13.6 \mathrm{mg} / \mathrm{L})$ and a small amount of coumaric acid $(<0.2 \mathrm{mg} / \mathrm{L})$ suggested that $R c$ TAL became into the rate-limiting step in this artificial pathway, especially after $24 \mathrm{~h}$ (Table 3).

\section{Conclusions}

We have successfully established a novel pathway and constructed an E. coli strain for the de novo production of caffeic acid via metabolic engineering approaches. We first identifed that $4 \mathrm{HPA} 3 \mathrm{H}$ can function as a $\mathrm{C} 3 \mathrm{H}$ which exhibited decent activity toward $p$-coumaric acid and tyrosine, thus gains great potential for metabolic engineering and biocatalysis applications. In addition, we compared the TALs from $R$. capsulatus $(R c)$ and $R$. sphaeroids $(R s)$ that are able to catalyze the deamination of both tyrosine and L-dopa. RcTAL exhibited higher activities toward both substrates. Then a dual pathway leading from tyrosine to caffeic acid was proposed and introduced into E. coli. The artificial pathway extended the native tyrosine pathway of $E$. coli and produced $12.1 \mathrm{mg} / \mathrm{L}$ of caffeic acid from simple carbon sources. Further improvement of production was accomplished via alleviating feedback inhibition and redirecting carbon flux into tyrosine biosynthesis. Finally, the titer of caffeic acid reached $50.2 \mathrm{mg} / \mathrm{L}$ in shake flasks after 48-hour cultivation.

The established pathway obviated the use of two cytochrome P450-dependent monooxygenases $(\mathrm{C} 4 \mathrm{H}$ and $\mathrm{C} 3 \mathrm{H}$ ) and achieved the de novo biosynthesis of caffeic acid, which opened the possibility of microbial synthesis of more complex plant secondary metabolites derived from caffeic acid. However, for the production system to be more economically viable, productivity has to be further improved. We have identified that RcTAL is the rate-limiting enzyme in the pathway once the tyrosine availability issue was solved. To meet the process metrics and avoid the accumulation of the intermediates (tyrosine and $L$-dopa), we will explore more TALs for higher catalytic activity via bioprospecting and protein engineering approaches. In addition to the tyrosine overproducers we generated in this study, the strains employed to produce tyrosine in amino acid industry are also ready to be used as hosts for caffeic acid production. With proper process optimization, industrially relevant production should be expectable.

\section{Materials and methods \\ Chemicals and enzymes}

The following commercially available chemicals and enzymes were used in this study: L-dopa (ACROS Organics); tyrosine (Sigma-Aldrich), caffeic acid (TCI), p-coumaric acid (MP Biochemicals), IPTG (Zymo Research Co.), restriction enzymes (NEB), Hot Start KOD Plus DNA polymerase (EMD Chemicals Inc.), Rapid DNA ligase Kit (Roche). All the enzymes were used according to the instructions provided by the manufacturers.

\section{Strains, plasmids, media, and growth conditions}

E. coli XL1-Blue (Stratagene) was used for gene cloning and plasmid propagation. Wild type E. coli strain BW25113 (E. coli Genetic Resource Center) and its derivatives were employed for either enzyme assays or shake flask experiments. Plasmids pZE12-luc and pCS27 were used for gene over-expression in E. coli $[32,33]$. The characteristics of all the strains and plasmids used in this study are described in Table 4. E. coli cells for gene cloning, plasmid propagation, and inoculum preparation were grown in Luria-Bertani (LB) medium at $37^{\circ} \mathrm{C}$. The fermentation medium was modified M9 minimal salt medium containing (per liter): glycerol (10 g), glucose (2.5 g), $\mathrm{NH}_{4} \mathrm{Cl}(1 \mathrm{~g}), \mathrm{Na}_{2} \mathrm{HPO}_{4}(6 \mathrm{~g}), \mathrm{KH}_{2} \mathrm{PO}_{4}(3 \mathrm{~g}), \mathrm{NaCl}(0.5 \mathrm{~g})$, $\mathrm{MgSO}_{4} \cdot 7 \mathrm{H}_{2} \mathrm{O}(2 \mathrm{mmol}), \mathrm{CaCl}_{2} \cdot 2 \mathrm{H}_{2} \mathrm{O}(0.1 \mathrm{mmol})$, vitamin B1 (2.0 mg), $\mathrm{H}_{3} \mathrm{BO}_{3}(1.25 \mathrm{mg}), \mathrm{NaMoO}_{4} \cdot 2 \mathrm{H}_{2} \mathrm{O}(0.15 \mathrm{mg})$, $\mathrm{CoCl}_{2} \cdot 6 \mathrm{H}_{2} \mathrm{O}(0.7 \mathrm{mg}), \mathrm{CuSO}_{4} \cdot 5 \mathrm{H}_{2} \mathrm{O}(0.25 \mathrm{mg})$, $\mathrm{MnCl}_{2} \cdot 4 \mathrm{H}_{2} \mathrm{O}(1.6 \mathrm{mg})$, and $\mathrm{ZnSO}_{4} \cdot 7 \mathrm{H}_{2} \mathrm{O}(0.3 \mathrm{mg})$. For the strains carrying plasmids, $100 \mu \mathrm{g} / \mathrm{ml}$ of ampicillin, 50 $\mu \mathrm{g} / \mathrm{ml}$ of kanamycin and/or $30 \mu \mathrm{g} / \mathrm{ml}$ of chloramphenicol were added if necessary. For all shake flask experiments, $200 \mu$ l overnight LB culture was inoculated into $10 \mathrm{ml}$ fermentation medium and grown at $37^{\circ} \mathrm{C}$ with shaking. After $\mathrm{OD}_{600}$ reached 0.4-0.5. IPTG was added into the cultures to a final concentration of $0.2 \mathrm{mM}$. Then the cultures were transferred to $30^{\circ} \mathrm{C}$ in a gyratory shaker at $250 \mathrm{rpm}$. Samples were collected after 24 and 48 hours, and then analyzed by HPLC.

\section{Molecular biology techniques}

General molecular biology techniques and DNA manipulations were carried out according to the standard protocols [34]. Deletion of kanamycin resistant gene from E. coli JW1316-1 was conducted using the method described by Kirill A. Datsenko and Barry L. Wanner [35]. Host cells were transformed with the plasmids by electroporation (EPPENDORF Electroporator 2510, 1.8 $\mathrm{kV}$ when using $0.1 \mathrm{~cm}$ cuvettes). 
Table 4 Strains and plasmids used in this study

\begin{tabular}{|c|c|c|}
\hline Plasmid or Strain & Relevant characteristics & Source \\
\hline \multicolumn{3}{|l|}{ Plasmids } \\
\hline pZE12-luc & ColE1 ori; Amp ${ }^{R}$; PLlacO1; luc & Lutz et al., 1997 \\
\hline pCS27 & p15A ori; Kan ${ }^{\text {; }} P_{L}$ lacO1; MCS1 & Shen et al., 2008 \\
\hline pZE-RCTAL & From pZE12, PLlacO1; tal(RC) & This study \\
\hline pZE-RsTAL & From pZE12, PLlacO1; tal(Rs) & This study \\
\hline pZE-EcHpaBC & From pZE12, PLlacO1; hpaB(Ec)-hpaC(Ec) & This study \\
\hline pZE-TH & From pZE12, PLlacO1; tal(Rc)-hpaB(EC)-hpaC(EC) & This study \\
\hline pCS-TPTA & From pCS27, PLlacO1; tyrA for-ppsA-tktA-aroG $G^{f o r}$ & This study \\
\hline \multicolumn{3}{|l|}{ Strains } \\
\hline XL1-Blue & 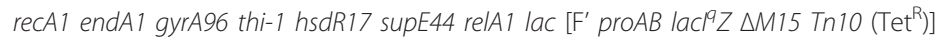 & Stratagene \\
\hline BW25113 & $\mathrm{F}-, \Delta(\operatorname{araD}-\mathrm{araB}), \Delta \mathrm{lacZ}(: \cdot r r n B-3), \lambda-, r p h-1, \Delta(r h a D-r h a B), h s d R$ & Yale CGSC \\
\hline JW1316-1 & BW25113, $\Delta t y r R:: k a n$ & Yale CGSC \\
\hline YL-1 & BW25113, $\Delta$ tyrR::FRT (as JW1316-1, but $k^{2} n^{R}$ gene deleted) & This study \\
\hline YL-2 & BW25113 harboring pZE-TH & This study \\
\hline YL-3 & BW25113 harboring PCS-TPTA & This study \\
\hline$Y L-4$ & YL-1 harboring pCS-TPTA & This study \\
\hline YL-5 & BW25113 harboring pZE-TH and pCS-TPTA & This study \\
\hline YL-6 & YL-1 harboring pZE-TH and pCS-TPTA & This study \\
\hline
\end{tabular}

\section{Construction of plasmids}

To construct pZE-RcTAL and pZE-RsTAL, the genes encoding $R c$ TAL and $R s$ TAL were amplified by high-fidelity polymerase chain reaction (PCR) from the genomic DNAs of Rhodobacter capsulatus and Rhodobacter sphaeroides using the primers listed in Additional file 1: Table S1 [25]. Amplified fragments and pZE12-luc were digested with $K p n \mathrm{I}$ and $S p h \mathrm{I}$, and then ligated with Rapid DNA ligase. To construct pZE-EcHpaBC, the gene cluster $h p a B C$ was amplified from $E$. coli MG1655 genome directly. The amplified $h p a B C$ fragment was inserted into pZE12-luc vector between КриI and $S p h \mathrm{I}$ as well. The pZE-TH was constructed by cloning the gene cluster $h p a B C$ into the pZE-RcTAL using restriction enzymes $S p h I$ and $X b a I$. A ribosome binding site is located upstream of each gene to facilitate protein expression. The genes $t y r A$, aroG, pps $A$, and $t k t A$ were all amplified from E. coli MG1655 genomic DNA. Point mutations were introduced to tyrA (Met-53-Ile and Ala-354-Val) and aroG (Asp-146-Asn) by splicing and overlapping extension PCR (SOE-PCR), generating $t y r A^{f b r}$ and aro $G^{f b r}$ $[36,37]$. The genes $t y r A^{f b r}$ and $p p s A$ were first cloned into pCS27 simultaneously via three-piece ligation using restriction enzymes $K p n \mathrm{I}, \mathrm{NdeI}$, and SalI, generating the plasmid pCS-TP. Similarly, $t k t A$ and aro $G^{f b r}$ were then simultaneously inserted into pCS-TP using restriction enzymes XhoI, SphI, and HindIII resulting in pCS-TPTA.

\section{HPA3H In vitro assay}

The E. coli strain BW25113 carrying the plasmid pZE$E c \mathrm{HpaBC}$ was pre-inoculated into LB liquid medium containing $100 \mu \mathrm{g} / \mathrm{ml}$ of ampicillin and grown at $37^{\circ} \mathrm{C}$ overnight with shaking at $250 \mathrm{rpm}$. In the following day, $1 \mathrm{ml}$ of preinoculum was added to $50 \mathrm{ml}$ of fresh LB medium also containing $100 \mu \mathrm{g} / \mathrm{ml}$ of ampicillin. The culture was left to grow at $37^{\circ} \mathrm{C}$ till $\mathrm{OD}_{600}$ reached 0.6 and then induced with $0.5 \mathrm{mM}$ IPTG. Protein expression was conducted at $30^{\circ} \mathrm{C}$ for another $3 \mathrm{~h}$. The cells were harvested and resuspended in $2 \mathrm{ml}$ of buffer A (20 $\mathrm{mM} \mathrm{KH_{2 }} \mathrm{PO}_{4}, \mathrm{pH}=7.0$ ), and then lysed by French Press. The soluble fraction was collected by ultra-centrifugation and used as crude enzyme extract for the enzyme assay. Total protein concentration was estimated using the BCA kit (Pierce Chemicals). The total protein concentration of the crude extract is around $6172 \mu \mathrm{g} / \mathrm{ml}$. The enzyme activity was assayed according to the protocol described by Tai. et al. with a few modifications [26]. The $1 \mathrm{ml}$ reaction system contained $2 \mathrm{mM}$ NADH, $2 \mathrm{mM}$ FAD, $2 \mathrm{mM}$ substrate (tyrosine or $p$-coumaric acid) and $100 \mu \mathrm{l}$ of crude enzyme extract in buffer $\mathrm{A}$. The reaction was incubated at $30^{\circ} \mathrm{C}$ for $1.5 \mathrm{~min}$ and terminated by adding $50 \mu \mathrm{l} \mathrm{HCl} \mathrm{(20 \% )} \mathrm{to}$ the $1 \mathrm{ml}$ reaction system. The amount of products $(L-$ dopa and caffeic acid, respectively) were measured and quantified by HPLC.

\section{Whole-cell Bioconversion by 4HPA3H}

The E. coli strain BW25113 carrying the plasmid pZE$E c \mathrm{HpaBC}$ was pre-inoculated into LB liquid medium containing $100 \mu \mathrm{g} / \mathrm{ml}$ of ampicillin and grown at $37^{\circ} \mathrm{C}$ overnight with shaking at $250 \mathrm{rpm}$. Then $0.1 \mathrm{ml}$ of preinoculum was added to $10 \mathrm{ml}$ of fresh LB medium also containing $100 \mu \mathrm{g} / \mathrm{ml}$ of ampicillin. The culture was grown at $37^{\circ} \mathrm{C}$ till $\mathrm{OD}_{600}$ reached 0.6 and then induced 
with $0.5 \mathrm{mM}$ IPTG for 3 hours. After that, $100 \mathrm{uL}$ of $p$ coumaric acid $(10 \mathrm{~g} / \mathrm{L})$ was added to reach a final concentration of $100 \mathrm{mg} / \mathrm{L}$. Samples were collected at $3 \mathrm{~h}$ and analyzed by HPLC

\section{HPA3H In vivo assay}

The pre-inoculum of E. coli strain BW25113 carrying $\mathrm{pZE}-E c \mathrm{HpaBC}$ from an overnight culture was added in to $10 \mathrm{ml}$ of $\mathrm{LB}$ medium $(1: 100 \mathrm{~V} / \mathrm{V})$ and grown at $37^{\circ} \mathrm{C}$. IPTG was added to the cultures to a final concentration of $0.5 \mathrm{mM}$ until $\mathrm{OD}_{600}$ reached 0.6. The cultures were left at $30^{\circ} \mathrm{C}$ for around another 3 hours with shaking for protein expression till $\mathrm{OD}_{600}$ reached 3.0 (approximately equivalent to $1 \mathrm{~g} / \mathrm{L}$ cell). Then the cells were collected, washed, resuspended in $10 \mathrm{ml}$ of $\mathrm{NaCl}(0.9 \%)$ solution. 1 $\mathrm{mM}$ substrate (tyrosine or $p$-coumaric acid) was added to the cell resuspensions at $30^{\circ} \mathrm{C}$. Samples were collected after 1 and 2 hours, and then analyzed by HPLC.

\section{Enzyme assay of RcTAL and RsTAL}

The crude enzyme extracts of RcTAL and RsTAL were prepared as described before [25]. But the cells were resuspended in buffer $\mathrm{B}(50 \mathrm{mM}$, Tris- $\mathrm{HCl}, \mathrm{pH}=8.5)$. The $1 \mathrm{ml}$ reaction system contained $2 \mathrm{mM}$ substrate (tyrosine or $L$-dopa) and $100 \mu \mathrm{l}$ crude extract in buffer $B$. The reaction was incubated at $30^{\circ} \mathrm{C}$ for $1.5 \mathrm{~min}$ and the amount of products ( $p$-coumaric acid and caffeic acid, respectively) was measured by HPLC.

\section{HPLC analysis of products}

Tyrosine, $L$-dopa, $p$-coumaric acid, and caffeic acid generated in enzyme assays and fermentations were quantitatively analyzed by HPLC (Dionex Ultimate 3000 ) with a reverse-phase ZORBAX SB-C18 column and an Ultimate 3000 Photodiode Array Detector. The compounds were separated by elution with a methanol-water gradient (water containing $0.2 \%$ trifluoroacetic acid). The following gradient was used at a flow rate of $1 \mathrm{ml} / \mathrm{min}$ : 10 to $50 \%$ methanol for $15 \mathrm{~min}, 50$ to $10 \%$ methanol for 1 min, and 10\% methanol for an additional 4 min. Quantification for the four above-mentioned compounds was based on the peak areas of absorbance at 274, 280, 308 and $323 \mathrm{~nm}$, respectively. The data shown in this study were generated from duplicate or triplicate independent experiments.

\section{Additional material}

\section{Additional file 1: Table S1 Primers used in this study}

\section{Acknowledgements}

This work was supported by the start-up funds from the Faculty of Engineering, University of Georgia, Athens and a research grant provided by the University of Georgia Research Foundation, Inc. We would like to thank Rachit Jain for proofreading the manuscript.

\section{Author details}

${ }^{1}$ Department of Biological and Agricultural Engineering, the University of Georgia, Athens, GA 30602, USA. ${ }^{2}$ Biochemical Engineering Program, Faculty of Engineering, the University of Georgia, Athens, GA 30602, USA.

\section{Authors' contributions}

$Y Y$ and $Y L$ conceived the study. $Y L$ conducted the experiments under the direction of $Y Y$. YL did literature review and drafting of the manuscript. $Y Y$ made revisions. Both authors read and approved the final manuscript.

\section{Competing interests}

The University of Georgia has filed a United State provisional patent on this technology.

Received: 18 January 2012 Accepted: 4 April 2012

Published: 4 April 2012

\section{References}

1. Mori $H$, Iwahashi $H$ : Antioxidant activity of caffeic acid through a novel mechanism under uva irradiation. J Clin Biochem Nutr 2009, 45:49-55.

2. Gulcin I: Antioxidant activity of caffeic acid (3,4-dihydroxycinnamic acid). Toxicology 2006, 217:213-220

3. Ikeda K, Tsujimoto K, Uozaki M, Nishide M, Suzuki Y, Koyama AH, Yamasaki $\mathrm{H}$ : Inhibition of multiplication of herpes simplex virus by caffeic acid. Int J Mol Med 2011, 28:595-598.

4. Rajendra-Prasad N, Karthikeyan A, Karthikeyan S, Reddy BV: Inhibitory effect of caffeic acid on cancer cell proliferation by oxidative mechanism in human HT-1080 fibrosarcoma cell line. Mol Cell Biochem 2011, 349:11-19.

5. Chao PC, Hsu CC, Yin MC: Anti-inflammatory and anti-coagulatory activities of caffeic acid and ellagic acid in cardiac tissue of diabetic mice. Nutr Metab (Lond) 2009, 6:33

6. Wu J, Omene C, Karkoszka J, Bosland M, Eckard J, Klein CB, Frenkel K. Caffeic acid phenethyl ester (CAPE), derived from a honeybee product propolis, exhibits a diversity of anti-tumor effects in pre-clinical models of human breast cancer. Cancer Lett 2011, 308:43-53.

7. Celik S, Erdogan S, Tuzcu M: Caffeic acid phenethyl ester (CAPE) exhibits significant potential as an antidiabetic and liver-protective agent in streptozotocin-induced diabetic rats. Pharmacol Res 2009, 60:270-276.

8. Bourgaud F, Hehn A, Larbat R, Doerper S, Gontier E, Kellner S, Matern U: Biosynthesis of coumarins in plants: a major pathway still to be unravelled for cytochrome P450 enzymes. Phytochem Rev 2006, 5:293-308.

9. Kojima M, Takeuchi W: Detection and characterization of p-coumaric acid hydroxylase in mung bean, Vigna mungo, seedlings. J Biochem 1989, 105:265-270

10. Kim YH, Kwon T, Yang HJ, Kim W, Youn H, Lee JY, Youn B: Gene engineering, purification, crystallization and preliminary $\mathrm{X}$-ray diffraction of cytochrome P450 p-coumarate-3-hydroxylase $(\mathrm{C} 3 \mathrm{H})$, the Arabidopsis membrane protein. Protein Expr Purif 2011, 79:149-155.

11. Kneusel RE, Matern U, Nicolay K: Formation of trans-caffeoyl-CoA from trans-4-coumaroyl-CoA by Zn2 + -dependent enzymes in cultured plant cells and its activation by an elicitor-induced $\mathrm{pH}$ shift. Arch Biochem Biophys 1989, 269:455-462.

12. Berner M, Krug D, Bihlmaier C, Vente A, Muller R, Bechthold A: Genes and enzymes involved in caffeic acid biosynthesis in the actinomycete Saccharothrix espanaensis. J Bacteriol 2006, 188:2666-2673.

13. Wang J, Lu DQ, Zhao $H$, Ling XQ, Jiang B, Ouyang PK: Application of response surface methodology optimization for the production of caffeic acid from tobacco waste. Af J Biotechnol 2009, 8:1416-1424.

14. Yoshimoto M, Kurata-Azuma R, Fujii M, Hou DX, Ikeda K, Yoshidome T, Osako M: Enzymatic production of caffeic acid by koji from plant resources containing caffeoylquinic acid derivatives. Biosci Biotechnol Biochem 2005, 69:1777-1781.

15. Sachan A, Ghosh S, Sen SK, Mitra A: Co-production of caffeic acid and phydroxybenzoic acid from p-coumaric acid by Streptomyces caeruleus MTCC 6638. Appl Microbiol Biotechnol 2006, 71:720-727.

16. Yan Y, Chemler J, Huang L, Martens S, Koffas MA: Metabolic engineering of anthocyanin biosynthesis in Escherichia coli. Appl Environ Microbiol 2005, 71:3617-3623. 
17. Yan $Y$, Kohli A, Koffas MA: Biosynthesis of natural flavanones in Saccharomyces cerevisiae. Appl Environ Microbiol 2005, 71:5610-5613.

18. Yan Y, Huang L, Koffas MA: Biosynthesis of 5-deoxyflavanones in microorganisms. Biotechnol J 2007, 2:1250-1262.

19. Yan Y, Li Z, Koffas MA: High-yield anthocyanin biosynthesis in engineered Escherichia coli. Biotechnol Bioeng 2008, 100:126-140.

20. Choi O, Wu CZ, Kang SY, Ahn JS, Uhm TB, Hong YS: Biosynthesis of plantspecific phenylpropanoids by construction of an artificial biosynthetic pathway in Escherichia coli. J Ind Microbiol Biotechnol 2011, 38:1657-1665.

21. Santos CN, Koffas M, Stephanopoulos G: Optimization of a heterologous pathway for the production of flavonoids from glucose. Metab Eng 2011, 13:392-400.

22. Nakagawa A, Minami H, Kim JS, Koyanagi T, Katayama T, Sato F, Kumagai H: A bacterial platform for fermentative production of plant alkaloids. Nat Commun 2011, 2:326.

23. Munoz AJ, Hernandez-Chavez G, de Anda R, Martinez A, Bolivar F, Gosset G: Metabolic engineering of Escherichia coli for improving $L-3,4-$ dihydroxyphenylalanine (L -DOPA) synthesis from glucose. $J$ Ind Microbiol Biotechnol 2011, 38:1845-1852.

24. Leonard E, Runguphan W, O'Connor S, Prather KJ: Opportunities in metabolic engineering to facilitate scalable alkaloid production. Nat Chem Biol 2009, 5:292-300.

25. Xue Z, McCluskey M, Cantera K, Sariaslani FS, Huang L: Identification, characterization and functional expression of a tyrosine ammonia-lyase and its mutants from the photosynthetic bacterium Rhodobacter sphaeroides. J Ind Microbiol Biotechnol 2007, 34:599-604.

26. Louie TM, Xie XS, Xun L: Coordinated production and utilization of $\mathrm{FADH} 2$ by $\mathrm{NAD}(\mathrm{P}) \mathrm{H}$-flavin oxidoreductase and 4-hydroxyphenylacetate 3-monooxygenase. Biochemistry 2003, 42:7509-7517.

27. Prieto MA, Perez-Aranda A, Garcia JL: Characterization of an Escherichia coli aromatic hydroxylase with a broad substrate range. J Bacteriol 1993, 175:2162-2167.

28. Liebgott PP, Amouric A, Comte A, Tholozan JL, Lorquin J: Hydroxytyrosol from tyrosol using hydroxyphenylacetic acid-induced bacterial cultures and evidence of the role of 4-HPA 3-hydroxylase. Res Microbiol 2009, 160:757-766.

29. Noel JP, Louie GV, Bowman ME, Moore BS, Moffitt MC: Substrate switched ammonia lyases and mutases. United States Patent Application 2009, No. 2009/0011400 A1.

30. Chavez-Bejar MI, Lara AR, Lopez H, Hernandez-Chavez G, Martinez A, Ramirez OT, Bolivar F, Gosset G: Metabolic engineering of Escherichia coli for L-tyrosine production by expression of genes coding for the chorismate mutase domain of the native chorismate mutase-prephenate dehydratase and a cyclohexadienyl dehydrogenase from Zymomonas mobilis. Appl Environ Microbiol 2008, 74:3284-3290.

31. Lutke-Eversloh T, Stephanopoulos G: L-tyrosine production by deregulated strains of Escherichia coli. Appl Microbiol Biotechnol 2007, 75:103-110.

32. Shen CR, Liao JC: Metabolic engineering of Escherichia coli for 1-butanol and 1-propanol production via the keto-acid pathways. Metab Eng 2008, 10:312-320.

33. Lutz $\mathrm{R}$, Bujard $\mathrm{H}$ : Independent and tight regulation of transcriptional units in Escherichia coli via the LacR/O, the TetR/O and AraC/I1-I2 regulatory elements. Nucleic Acids Res 1997, 25:1203-1210.

34. Sambrook J, Fritsch EF, Maniatis T: Molecular cloning: a laboratory manual. 2 edition. NY: Cold Spring Harbor Laboratory; 1989.

35. Datsenko KA, Wanner BL: One-step inactivation of chromosomal genes in Escherichia coli K-12 using PCR products. Proc Natl Acad Sci USA 2000, 97:6640-6645.

36. Heckman KL, Pease LR: Gene splicing and mutagenesis by PCR-driven overlap extension. Nat Protoc 2007, 2:924-932.

37. Lutke-Eversloh T, Stephanopoulos G: Feedback inhibition of chorismate mutase/prephenate dehydrogenase (TyrA) of Escherichia coli: generation and characterization of tyrosine-insensitive mutants. Appl Environ Microbiol 2005, 71:7224-7228.

doi:10.1186/1475-2859-11-42

Cite this article as: Lin and Yan: Biosynthesis of caffeic acid in Escherichia coli using its endogenous hydroxylase complex. Microbial Cell Factories 2012 11:42.

\section{Submit your next manuscript to BioMed Central and take full advantage of:}

- Convenient online submission

- Thorough peer review

- No space constraints or color figure charges

- Immediate publication on acceptance

- Inclusion in PubMed, CAS, Scopus and Google Scholar

- Research which is freely available for redistribution

Submit your manuscript at www.biomedcentral.com/submit
Biomed Central 